\section{O Enigma da quimbanda: formas de existência e de exposição de uma modalidade religiosa afro- brasileira no Rio Grande do Sul'}

\author{
Emerson Alessandro Giumbelli \\ Universidade Federal do Rio Grande do Sul | Porto Alegre, \\ RS, Brasil \\ emerson.giumbelli@yahoo.com.br \\ ORCID: https://orcid.org/0000-0002-6980-5494
}

Leonardo Oliveira de Almeida

Universidade Federal do Ceará | Fortaleza, CE, Brasil

leonardoalmeida_cs@yahoo.com.br

ORCID: https://orcid.org/0000-0002-0958-4888
Dol

http://DX.DOI.ORG/

$10.11606 / 1678-9857$

RA.2021.186652

1 | Costaríamos de

deixar, desde já, nossos

agradecimentos às mães e aos

pais de santo, aos donos de

empresas de mídia e a todos

os alabês que, amigavelmente,

nos concederam as entrevistas

mencionadas neste artigo.

Também aos interlocutores e

interlocutoras que direta ou

indiretamente contribuíram

para a feitura deste artigo,

incluindo colegas do Núcleo

de Estudos da Religião da

UFRCS, incluindo colegas

do Núcleo de Estudos da

Religião da UFRCS e do Grupo

de Estudos Afro - CEAFRO.

Quimbanda, no Rio Grande do Sul, é uma modalidade ritual que assumiu um estatuto sem par no restante do Brasil. Designando o culto de exus e pombagiras, a quimbanda alcançou um lugar proeminente em relação a outras expressões afrorreligiosas, como são o batuque e a umbanda. O objetivo deste texto é apontar as condições de possibilidade da quimbanda, mostrando como ela corresponde a um deslocamento em relação a princípios caros uns ao batuque, outros à umbanda. Também as formas de exposição de exus e pombagiras, que encadeiam manifestações espirituais, registros fotográficos e divulgação na internet, são abordadas como parte constitutiva do desenvolvimento da quimbanda. As análises baseiam-se na discussão de bibliografia sobre a quimbanda, na etnografia de rituais e em entrevistas com religiosos, buscando contribuir para o debate acerca das modalidades religiosas geradas pelo culto aos orixás no Brasil.

The enigma of Quimbanda: forms of existence and showing of an African-Brazilian religious modality in Rio Grande do Sul 


\section{INTRODUÇÃO}

O foco deste texto são as formas rituais em que se expressam as religiões afrobrasileiras no Rio Grande do Sul. Interessa-nos analisar um aspecto peculiar do campo afro-religioso gaúcho, aspecto que se revela inclusive em termos estatísticos. Em 2010, um projeto realizou o mapeamento de terreiros (unidades de culto de "religiões afrobrasileiras e afro-indígenas") em quatro regiões metropolitanas, incluindo Porto Alegre, Recife, Belo Horizonte e Belém. ${ }^{2}$ No que se refere à capital gaúcha, foram catalogadas 1342 casas, maior número entre os quatro universos, magnitude que se confirma em outros levantamentos. Às perguntas "qual a religião do seu terreiro/casa?" e "que outras formas religiosas praticam-se neste terreiro/casa?", as indicações somadas chegaram ao número de 2743 respostas. As referências mais frequentes foram "umbanda", com 36\% das respostas; em seguida, "batuque", com $30 \%$. Ao passo que a umbanda é religião nacionalmente disseminada, o batuque é a denominação que, no Rio Grande do Sul, constituiria um análogo ao candomblé na Bahia e a outras expressões locais presentes em muitas metrópoles brasileiras. Contudo, em terceiro lugar nas respostas, com expressivos $28 \%$, aparece um termo que não consta nos resultados de outras cidades e adquiriu sentido próprio e singular no Rio Grande do Sul: "quimbanda".

Quimbanda é, para qualquer pessoa que esteja a par da literatura umbandista, ou de seus estudos nos campos da história e das ciências sociais, uma palavra conhecida. Ocorre que, geralmente, ela se consolidou como uma categoria de acusação. É impossível precisar quando isso se firma, mas há registros que remetem aos anos 1940, ou seja, ao período em que a umbanda busca se apresentar como religião autônoma e com doutrina própria. De acordo com as formulações que acompanham essa institucionalização, a quimbanda seria uma espécie de negativo da umbanda, tanto em termos morais ("trabalha para o mal"), quanto em termos cosmológicos (um panteão simétrico e invertido de entidades). Com base nisso, em seu amplo estudo, Capone (2004: 100) reitera uma conclusão que traduz uma apreciação generalizada: "É evidente que nenhum centro se dirá de quimbanda em razão de sua associação com a magia negra". Como mostram as estatísticas mencionadas acima, isso não é verdade para a região metropolitana de Porto Alegre. Nessa região, e em outras cidades gaúchas onde as religiões afro-brasileiras são significativas, "quimbanda", entendida como o culto dirigido especificamente a exus e pombagiras, é algo que se declara.

Isso facilmente se constata em incursões pelo universo afro-gaúcho. A quimbanda é considerada, no Rio Grande do Sul, como algo com grande vitalidade. Em sua tese, Almeida (2019) deparou-se com a pujança e expansão desses rituais. O autor buscou compreender a atuação dos tambores utilizados nas religiões afro-brasileiras do Rio Grande do Sul, inclusive na saudação de exus e pombagiras, em um contexto de transformações no campo religioso e de intenso uso de "novas mídias" e tecnologias. A partir de uma perspectiva alargada de mídia, mais alinhada com a noção de mediação 
(Meyer, 2020; Stolow, 2005; Engelke, 2010), o trabalho faz uma análise acerca de certos agentes e objetos em constante diálogo com diferentes expressões do universo material afro-gaúcho. Nesse percurso, observações acerca da quimbanda e suas expressões materiais tiveram papel de destaque e fornecerão alguns dos argumentos e reflexões presentes neste artigo.

Partindo de tal quadro, este tex to tem como objetivo contribuir para a discussão do que chamaríamos de "o enigma da quimbanda". Que condições ocorreram para que algo categoricamente negativo em outros contextos adquirisse certa positividade no Rio Grande do Sul? Quais as relações entre tais condições e as configurações de devoção e de culto às quais está associada a quimbanda gaúcha? Além disso, que formas expressivas foram e vêm sendo associadas à quimbanda gaúcha, contribuindo para sua afluência? Embora façamos considerações que envolvem certos aspectos históricos, nossa referência está calcada mais no presente das feições do campo afrogaúcho. Se recorremos à história, não será para estabelecer conclusões genealógicas, mas para encontrar os sinais de elementos que nos parecem estruturais para dar conta da existência, em um sentido que será necessário precisar, da quimbanda.

Com base nesses objetivos, apontamos dois conjuntos de interlocuções. Um primeiro tem a ver com estudos sobre a configuração de formas rituais - e seus correspondentes em termos de categorias de nominação - no universo religioso afrobrasileiro (Maggie, 1992; Silva, 1995; Serra, 1995; Brumana e Martinez, 1995; Carvalho 1995; Birman, 1997; Giumbelli, 1997). Trata-se, mais propriamente, de um multiverso, conformado por uma proliferação de termos e de práticas, não necessariamente em compasso. Suas fronteiras tampouco são bem definidas, como mostram suas relações com outras referências, em especial o espiritismo de inspiração kardecista. Nesse campo, cada termo - candomblé, umbanda, espiritismo, etc - inspira uma investigação capaz de mostrar muito sobre o estatuto (frequentemente contestado) e as configurações de formas rituais (frequentemente heteróclitas). Queremos tomar como alvo a palavra "quimbanda" no contexto das condições de práticas afro-religiosas estabelecidas no Rio Grande do Sul.

Um segundo conjunto de discussões tem a ver com uma abordagem material das religiões, no modo sintetizado por autores como Engelke (2010) e Meyer (cf. Giumbelli, Rickli e Toniol, 2019). Trata-se de um veio teórico que recusa a separação entre conteúdo e forma, entre mensagem e meio. Com isso, ganham relevo questões acerca dos meios de expressão e dos modos de exposição das religiões. Aplicando essa perspectiva a nossa investigação acerca da quimbanda, privilegiamos o modo como as entidades cultuadas nessa modalidade ritual se mostram, por meio de performances, com suas formas de produção, registro e disseminação. É sobretudo na segunda parte de nossa análise que essa perspectiva renderá seus frutos.

Em termos metodológicos, este texto se sustenta em dois procedimentos. Primeiro, a discussão da bibliografia dedicada à caracterização da configuração dos 
cultos afro-gaúchos. Sem deixar de levar em conta um número maior de referências, concentraremos essa discussão em duas teses (Barbosa, 2012; Leistner, 2014), cujas análises e materiais nos parecem fundamentais para uma investigação sobre a quimbanda. Segundo, a exposição de aspectos pertinentes do trabalho que resultou em outra tese, que já foi mencionada acima (Almeida, 2019). Ao ter se dedicado por quatro anos às atividades dos tamboreiros que atuam em religiões afro-brasileiras na região metropolitana de Porto Alegre, o trajeto de sua elaboração deparou-se com "o enigma da quimbanda". O presente texto nasce exatamente da pesquisa etnográfica relacionada a essa tese, infletida por questões geradas na interlocução com discussões sobre a configuração de formas rituais e modos de exposição da religião.

\section{QUIMBANDA NA LINHA CRUZADA}

Ainda que, como já adiantamos, nossa démarche não seja genealógica, alguns elementos históricos nos parecem imprescindíveis para adentramos no "enigma da quimbanda". Entre eles está o que podemos chamar de um certo "equilíbrio" entre batuque e umbanda em termos de seu enraizamento no campo afro-religioso em Porto Alegre e em outras cidades onde sua presença é significativa. ${ }^{3}$ Equilíbrio no sentido de que, ao contrário de outros contextos, uma referência mais africanizada (o batuque) e outra menos africanizada (a umbanda) mostraram-se igualmente arraigadas. ${ }^{4} \mathrm{O}$ batuque gaúcho, como variante local do culto jeje-nagô, traça genealogias que partem ao menos do final do século XIX. Embora os templos atuais não tenham biografias longas, sacerdotes e sacerdotisas do batuque marcam de forma indelével a história das cidades e de sua cultura. Quando a umbanda se constitui em Porto Alegre, ela se depara assim com a presença firme de práticas referidas ao batuque ou a suas "nações". Isso ocorre a partir dos anos 1930, embora a primeira federação - a União de Umbanda - só venha a ser fundada em 1953. A umbanda que então predomina em Porto Alegre e outras regiões é "branca", recusando práticas estabelecidas no batuque como o uso de tambores e sacrifícios animais.

Segundo Leistner (2014), contudo, já desde o final dos anos 1950, desponta no Rio Grande do Sul outra possibilidade, assim descrita: "A Linha Cruzada surge de uma aproximação entre o Batuque e a Umbanda motivada pelas trajetórias de determinados agentes religiosos que, após a iniciação em uma dessas vertentes, aderiram à segunda passando a arregimentar em seus templos ambas as práticas." (:133). Embora com uma porcentagem bem menor (menos de 3\%) das respostas, "linha cruzada" é uma categoria que aparece também nos resultados do mapeamento acima citado, novamente apenas para Porto Alegre (Brasil, 2011). Tal porcentagem destoa das observações de Leistner, que estima que "na atual formação do segmento dos terreiros gaúchos, a Linha Cruzada corresponde a cerca de $80 \%$ das configurações religiosas presentes nas unidades de culto existentes" (:158). Embora não haja consenso

3| Trata-se, basicamente, da região litorânea delimitada pela capital metropolitana em direção ao sul, cobrindo outras cidades importantes como Pelotas e Rio Grande. No Rio Grande do Sul estão os 14 municípios com mais alto índice de adeptos de religiões afro-brasileiras, segundo o Censo do IBCE de 2010. Ver: https://gauchazh. clicrbs.com.br/geral/ noticia/2012/06/dados-doibge-colocam-municipiosdo-estado-como-campeoes em-credos-3806966.html

$4 \mid$ Casos contrastivos seriam de um lado, Salvador, com predomínio do candomblé; de outro, Rio de Janeiro e São Paulo, com prevalência histórica da umbanda. 
sobre a pertinência da categoria para designar uma forma específica, pesquisadores do campo afro-gaúcho concordam que é muito comum encontrarmos terreiros nos quais ambas as modalidades rituais, batuque e umbanda, são realizadas, geralmente com inclusão da quimbanda. As casas pesquisadas por Barbosa (2012), nas quais seus sacerdotes mantêm vínculos - diferenciais mas não excludentes - com entidades da umbanda e do batuque, poderiam servir de exemplo, embora não se assumam como "Linha Cruzada". Um ponto importante é que, embora a quimbanda esteja estabelecida como forma ritual, o termo aparece bem menos do que batuque e umbanda para designar os lugares de culto (templos).

Na verdade, há diferenças importantes entre os dois trabalhos quanto ao modo como entendem a linha cruzada. Para Leistner, "Linha Cruzada" é uma espécie de antecessora da quimbanda, a cuja caracterização como um sistema religioso próprio sua tese se dedica. Já para Barbosa, "linha cruzada" é a expressão de uma lógica que opera simultaneamente por conexões e separações, aquilo que permite entender a passagem entre entidades cultuadas sem produzir uma confusão entre elas. Para nós, ambos os trabalhos são valiosos. Ao situar nosso empreendimento em relação a eles, sustentamos: de um lado, questionamos a autonomização que Leistner atribui à quimbanda como sistema religioso; de outro, mantemos o interesse nas condições de possibilidade da quimbanda, questão que Barbosa desconsidera. Poderíamos igualmente afirmar: concordamos com Barbosa quanto à lógica que opera por conexões e separações, mas insistimos na pergunta de Leistner acerca das formas de existência da quimbanda. Ou seja, ainda que essa existência assuma uma forma que depende fundamentalmente de outras, não há como negar que ela se cristalizou a ponto de receber uma nominação bastante recorrente - a julgar pelos dados de Brasil (2011), tão significativa quanto "umbanda" e "batuque" - no campo afro-gaúcho.

Nosso procedimento consistirá em partir de certos traços das entidades cultuadas na quimbanda a fim de caracterizar suas condições de possibilidade. Essas entidades, segundo a terminologia consagrada pelos praticantes de seus rituais, são principalmente "exus" e "pombagiras", mas também "eguns". Ao passo que "exus" e "pombagiras" são termos que, no contexto afro-gaúcho, remetem à umbanda, "eguns" é algo que remete ao batuque. Por outro lado, como se sabe, "exu" é também o nome de um dos orixás cultuados na tradição jeje-nagô à qual se filia o batuque, enquanto que, para batuqueiros, "espíritos de mortos" - "eguns" - é uma definição que se aplicaria a todas as entidades reverenciadas na umbanda. Isso nos leva a uma observação importante: não pressupomos que umbanda e batuque sejam tipos correspondentes a modelos de religião puros. Concordamos com Barbosa e outros (por exemplo, Chiesa, 2012, para a umbanda; Serra, 1995, para o candomblé) que o campo afro-religioso é composto por formações sempre heteróclitas que permitem passagens entre elas e para fora delas. Mesmo assim, a recorrência de algumas categorias mostra a cristalização de certas configurações. Abandonemos a ideia de modelos, mas mantenhamos a 
noção de princípios. Na sequência, tomaremos certos traços cruciais da umbanda e do batuque para demonstrar como as entidades referidas à quimbanda operam uma espécie de curto-circuito - por meio do qual o acionamento de princípios como "evolução" e "feitura" geram novas possibilidades - que propicia as formas rituais que a caracterizam. Para tanto, nos serviremos de algumas referências que Leistner e outros autores resumem, com base no vocabulário nativo, nas expressões "exu da alta" e "exu cruzado".

\section{EXU DA ALTA}

Ao apresentar o trajeto que teria levado da Linha Cruzada à quimbanda, Leistner (2014) ilustra parte das inovações ocorridas a partir da segunda metade dos anos 1960 em diversos terreiros da região metropolitana de Porto Alegre com o caso de leda de Ogum. Nela, tida como uma das primeiras quimbandeiras da região (:147), se incorporava o Exu Rei das Sete Encruzilhadas ("Seu Sete"). Registra a tese de Leistner (2014:148):

Como Mãe leda refere em suas narrativas, as diferenças entre seu Exu e os Exus que até então participavam das sessões umbandistas consistia no fato de que "Seu Sete" poderia ser compreendido como um Exu mais evoluído, um Exu da alta, em oposição àqueles, considerados como entidades sem luz e localizados na mais baixa hierarquia da espiritualidade, segundo as representações amplamente disseminadas na região pela Umbanda "branca".

Essa distinção entre dois tipos de exus aparece também em um dos casos acompanhados na tese de Barbosa (2012), o de Mãe Rita, tensionada por sua relação com duas pombagiras: "E eu que sempre sonhei com uma pombagira bonita, passei a ter um espírito bêbado, caindo pelo terreiro" (:33).

Uma noção fundamental da ideia de "exu da alta" é a de evolução. Eis aí um princípio importante da umbanda, em dois planos. Primeiro, o cosmológico, que organiza a relação entre um conjunto de entidades, nas quais se destacam os caboclos e os preto-velhos em sua oposição com os exus. Diz-se que os primeiros são "mais evoluídos" que os segundos. Essa evolução, no entanto, é relativa, o que nos leva ao segundo plano, o da moral. Caboclos e preto-velhos manifestam-se para "fazer caridade" e, ao ajudar as pessoas, eles contribuem para sua própria evolução. O princípio da evolução é apropriado do espiritismo kardecista, notando-se que a umbanda, mesmo a "branca", empreende uma transformação ao reconhecer a força e render um culto a entidades, indígenas e negras, que o espiritismo, em geral, confinava a um papel menor.

Referindo-se ao passado da umbanda gaúcha, Leistner (2014: 140) afirma que, na prática ritual, "os Exus só chegavam ao final das sessões para limpar o terreiro, arrastando-se e bebendo cachaça pelo chão, sendo tratados como escravos dos guias de luz, verificando-se que nem mesmo existiam sessões rituais específicas para essas 
entidades." Afirmação semelhante pode ser ouvida de diversos pais e mães de santo. O pai de santo e tamboreiro da "velha guarda" do batuque, Alfredo Ferreira ${ }^{5}$, por exemplo, afirmou que:

Ele chegava uma vez no mês pra limpar a casa. No fim, terminava a sessão da umbanda e ele chegava pra limpar a casa. Os exus não eram materializados como estão hoje. O exu tomava cachaça no chão, andava todo torto. Eaí, foi evoluindo. As pessoas fizeram a evolução do exu. [...] O exu era uma calça preta, uma camisa vermel ha, descalço e deu. Hoje, exu bota sapato, exu bota terno, exu toma cerveja. Não tinha nada disso, era cachaça pura e deu. Não tinha festa de exu.

É comumente dito por pais e mães de santo que os exus se vestiam de maneira simples e com poucas peças, possuíam presença breve e controlada durante os rituais e andavam descalços ou, descrito de outra forma, sem necessariamente ser redundante, não usavam sapatos.

O "exu da alta", de que depende a quimbanda, significa uma transformação. $\mathrm{Na}$ umbanda, exus e pombagiras podem ser positivados - por exemplo, se passam por um "batismo" (Ortiz 1978). Como se viu acima, não se lhes nega um papel ritual, como "lixeiros do astral". De toda forma, afirma-se sua subordinação aos caboclos e pretosvelhos, não sendo incomum sua designação como "escravos" daquelas entidades. $\mathrm{Na}$ quimbanda, ocorre uma libertação, rompendo-se essa subordinação dos exus e pombagiras. Essas entidades são promovidas na escala cosmológica, o que lhes impõe cobranças morais. A exemplo de caboclos e pretos-velhos, confia-se que exus e pombagiras podem "fazer o bem" - conforme avaliações sempre relativas, pois se reconhece que o bem para alguém é capaz de ser o mal para outrem. Novamente tal como caboclos e pretos-velhos, são chamados a "trabalhar" em trocas que não estão desprovidas de moralidade, pois dependem de "merecimentos" e "esforços" de parte a parte (entidades e humanos).

Essa equalização entre exus e pombagiras, de um lado, e, de outro, caboclos e preto-velhos não elimina a diferença entre essas entidades no plano da sua caracterização. Se a marginalidade é um traço que se aplica a todas, exus e pombagiras mantêm-se associados a formas mais urbanas e liminares, figuras que levam "vidas desconformes". No caso das pombagiras, a referência dominante é a prostituição. No caso dos exus, as referências são mais variadas, explorando as muitas possibilidades de combinação entre vulnerabilidade e astúcia. Na quimbanda, essas pombagiras e exus são vistos e tratados com nobreza, subvertendo a noção de escravo. ${ }^{6}$ Vejamos quais são as referências para essa nobreza, como elas são representadas e qual é sua relação com a moralidade expressa nos "merecimentos".

Pai Ceison de Xangô, pai de santo que tem seu terreiro em Alvorada, na região metropolitana de Porto Alegre, comenta sobre a biografia espiritual dos exus:

Os exus são do tempo antigo, é diferente de hoje em dia. Nos tempos antigos você tem muito barão, baronesa, capitão do mato. Então eles são dessa origem, por isso que na manifestação deles são dessa forma. Todo exu, ele era barão. Se não era barão, era capitão do mato. Se não era

6|O tamboreiro Alfredo, quando questionado sobre as possíveis explicações para o fenômeno do crescimento da quimbanda, afirmou que "o exu começou a crescer quando deixou de ser escravo e virou rei" (Alfredo, julho de 2018). 
capitão do mato, eles eram donos de boemia, de casas de jogo. Então não era essa vida popular. Não era assim na manifestação deles enquanto ser humano. Era uma outra época, então eram imperiais, reis, rainhas, baronesas, barões. Então por isso essa imponência, de serem mais autoritários, até mesmo [no jeito] de se vestir, de se impor e de se falar. Ou eles eram doutor... Tu não encontra um exu operário, um exu "serviços gerais". Vamos dizer, funções de serviço, não existia isso. ${ }^{7}$

A fala de Pai Geison não parece anunciar apenas um processo de evolução, mas também, com base nas pesquisas que estivemos realizando, um processo de valorização de personalidades míticas ligadas a certos modos de poder social. Esse "tempo antigo" e o alinhamento dos exus às vestes da elite foi evidenciado por Cesar de Xangô, pai de santo e dono de uma loja de axós (roupas para religião) em Porto Alegre. Pai Cesar também nos fala sobre a importância que os rituais praticados no terreiro da mãe de santo leda de Ogum, que é, tal como afirmam diversos mães e pais de santo entrevistados, uma das grandes referências na quimbanda gaúcha. ${ }^{8}$

Uma das principais ialorixás, zeladoras de exu, a Mãe leda de Ogum, que é do Seu Sete, eles é que começaram com essa questão mais visual, essa questão do Rei, essa coisa do Rei das Sete Encruzilhadas. Então as vestes, a decoração, aquele estilo de cadeira, Luiz XV, uma coisa mais medieval, veio dessa família religiosa que é muito numerosa. E isso foi se espalhando, as pessoas foram tomando gosto e tudo se copia ao longo do tempo. Então hoje se criou essa questão de que o dono da festa tem o seu momento, a sua entrada triunfal (corte). Quanto mais babado, quanto mais casacas, mais coletes, melhor.

Não foram poucos os pais e mães de santo que, quando entrevistados durante o processo de pesquisa que originou este artigo, destacaram a influência de Mãe leda e "Seu Sete" para a constituição de modelos evolutivos na quimbanda gaúcha. A essa mãe de santo também são atribuídas, por exemplo, a realização de festas de quimbanda em casas de shows e galpões, ou seja, fora do terreiro; a existência do cortejo"; e outros aspectos dessa "coisa mais visual", como o trono, as vestimentas e as características de realeza.

Diversos elementos que constituem o "exu da alta", ${ }^{10}$ tais como vestimentas, tronos, cetros, sacrifícios, decorações, local onde ocorrem as festas de quimbanda fazem parte do que é comumente chamado de merecimento, ou seja, o recebimento de presentes pelos trabalhos prestados. Esses exus "trajam merecimentos", assim descreve Teixeira (2005) a partir de sua pesquisa sobre o vestuário dos exus e pombagiras da quimbanda gaúcha. O exu quimbandeiro, portanto, "trabalha para evoluir", assim como nos tempos em que era um "exu de umbanda", mas agora possui autonomia em relação a outras entidades. Receber objetos cada vez mais bonitos, bem como a frequência com que se recebe novos presentes, é motivo de orgulho para pais, mães de santo e para os próprios exus.

Importante figura da monarquia inglesa, o "Seu Sete" da Mãe leda é tratado como um rei cujos atributos foram sendo adquiridos ao longo dos anos. A entidade
7| Entrevista, setembro

de 2018 , concedida a

Leonardo Almeida.

8| Entrevista, julho de 2018, concedida a Leonardo Almeida.

9|A corte (cortejo) faz referência a uma espécie de "entrada triunfal" dos exus e seus convidados mais ilustres durante uma festa de quimbanda.

10| Além de Leistner (2014) Silva (2003) e Bem (2012) constatam a importância do que grafam como "exu do alto" para a quimbanda. 
nasceu na umbanda, manifestando-se ao final dos rituais e, em certo momento de sua trajetória, passou a trabalhar no que anos mais tarde viria a ser a quimbanda, até tornar-se, tal como considera Mãe leda, o hors concours.

Meu exu usava avental, as bombachinha, sapatilha. Não chegava vestido de homem. Chegava todo torto, gritando, tomava cachaça no chão, comia vela, descarregava o terreiro e ia embora. Depois de anos ele pediu uma calça branca e uma camisa vermelha. Pediu a guia, vermelha e branca.... Quando eu comecei a fazer a magia dele, que ele foi pedindo, comecei a fazer mesa, presente no cruzeiro, que ele pedia. Papel de seda vermelho, uma bandeja, uma cachaça, um charuto, uma vela e um pedaço de carne e azeite de dendê. Eu comecei assim. Ele pedia e ele foi ganhando roupa, capa, cartola, sapato, charuto bom, uísque bom. Há 50 anos não tinha nada disso. Ele foi ganhando. E tem um estilista. Esse que faz a roupa do Seu Sete é estilista que faz roupa de escola de samba. Então, se pedir uma roupa de rei, ele sabe. A corte, ele (Seu Sete) fez. Seu Sete tinha sete mulheres (que entravam com ele na corte), sete rainhas feitas por ele, na casa dele. Nãoé eu que escolhi, foi ele. Ele foi pedindo. Seu Sete trabalhava no cruzeiro como um rei, não como um Zé Pilintra dançando samba."

Torna-se importante destacar que a realeza não se resume à imagem da monarquia europeia, como é bastante comum entre os exus quimbandeiros, mas também apresenta características que seguem modelos diversos de prestígio social e poder. Outro conhecido exu de Porto Alegre é o "Seu Belo", exu do pai de santo Neco de Oxalá12 Este pai de santo contou que seu exu se manifestou pela primeira vez em 1966, quando ainda tinha sete anos de idade. Sua mãe, Teresinha de Oxalá, conhecida mãe de santo da quimbanda portoalegrense, recebia o Exu Sete Cruzeiros e, como Leonardo Almeida. auxílio dessa entidade, fez uma negociação com Seu Belo. Uma vez que Pai Neco, à época, tinha apenas sete anos, Seu Belo deveria aguardar até a maturidade do seu novo "cavalo". Em troca, a entidade fez dois pedidos: seu próprio assentamento e, além disso, realizar trabalhos às sextas feiras. Até então, a casa de Mãe Teresinha realizava trabalhos com as entidades da umbanda às terças, com sessões destinadas aos pretos velhos, e às quintas, com sessões destinadas aos caboclos. A realização de um ritual destinado apenas aos exus, prática iniciada no final da década de 1960, se confunde com o surgimento e constituição da quimbanda como ritual específico em Porto Alegre.

Segundo Pai Neco, o Exu Sete Cruzeiros de sua mãe nunca aceitou ser tratado como uma realeza, tampouco trocar suas vestes: "A única mudança do exu da minha mãe, da vida toda, foi aceitar o preto [até então utilizava apenas o branco], em 89, e depois, na década de 90, aceitar o bonezinho". Por outro lado, "Seu Sete" tratava "Seu Belo" como um rei: "Seu Sete tratava Seu Belo como uma majestade. Chamava 'meu rei, o que o senhor precisa?"'. Ele prossegue:

Eu não concordo que exu seja um bicho, nunca aceitei. Nós construímos uma imagem de exu totalmente diferente do exu sendo chamado de diabo, de coisas do gênero, o exu que tomava cachaça no chão, comia vela, se arrastava. Então a partir dos anos 60, que a gente começou a fazer uma sessão pra exu, a gente começou a construir uma imagem de exu diferente, exu rei. Exu de 
sapato, exu de capa, exu de bengala, exu tratando as pessoas por senhoria, por reis e rainhas. Tira a questão do exu comer vela, tomar cachaça. Não! Exu tem que tomar uísque, tem que tomar espumante. Em 1967 nós dávamos, como axé, à chegada de exu, nós presenteamos eles, a capa, 0 chapéu, a bengala, o sapato, tudo era axé. Eles ganhavam por méritos, de trabalhos, de serviços. Então os exus tinham que se esmerar, mostrar trabalho, ajudar as pessoas pra ganhar o sapato, depois a capa. Na década de 70, em 76, 78, por aí, nas festas o Seu Belo chegava de limusine. Agora eu tenho um filho de santo, o Sidnei, que o (Exu) Maré chega de limusine em Tramandaí.

A realeza do Exu Belo não advém dos modelos reais europeus, tal como no caso do exu de Mãe leda. Sua majestade vem do fato de ser Lúcifer, o "grande arquiteto do universo": "A história dele é que ele era Lúcifer. A história que todo mundo conhece. Sempre foi tratado por majestade, por ser um exu maioral, o grande arquiteto do universo. A gente deu um nome carinhoso pra ele, de Seu Belo, pra não ser chamado de Lúcifer, que assustava as pessoas". Observamos aqui outro modelo de realeza, que se consolidaria na década de 1970 e 1980, em especial a partir do tratamento dado ao Seu Belo pelo Exu Sete Cruzeiros. Seu Belo passou a ter grandes festas em salões bem decorados, a receber presentes e a ter uma entrada triunfal com convidados ilustres e toques de clarim.

Seu Belo também passou a coroar outros exus, prática que, atualmente, é bastante comum na quimbanda gaúcha. ${ }^{13}$ Como reconhecimento pelos trabalhos prestados, a coroação confere à entidade um novo status, agora de "exu coroado". Uma das entidades coroada por Seu Belo, a Maria Mulambo, reforça a ressignificação do princípio da evolução. No Rio Grande do Sul, o imaginário da realeza contribuiu para que os exus assumissem aspectos morais anteriormente negados pela umbanda "branca". ${ }^{14}$ Maria Mulambo é também chamada de "Rainha do Lixo". Essa entidade mostra que é possível ser rainha e, ao mesmo tempo, manter a marginalidade, como se canta em seu ponto: "Ela ganhou uma coroa de ouro / Ganhou uma coroa de prata / Mas preferiu morar no lixo / Com sua coroa de lata". Maria Mulambo assume o trabalho do lixo, o que confere aos exus a possibilidade de reconfiguração moral dos processos evolutivos. Exu é "a exposição do que está em degradação" (Anjos, 2006: 87). O exu quimbandeiro parece atuar sobre a "iluminação evolutiva", propondo outros tipos de reconhecimento evolutivo aos exus que por muito tempo foram considerados despossuídos de luz.

Em suma, o "exu da alta" - e podemos acrescentar a "pombagira de luxo"opera uma transformação no arranjo umbandista, permitindo que essas entidades se relacionem com caboclos e pretos-velhos de outra forma: não mais como "escravos", mas como mais marginais. Nem a cosmologia ou a moralidade umbandistas são recusadas categoricamente, pois a marginalidade é delas um componente fundamental. Mas há um deslocamento, que produz cenas curiosas, a exemplo de "giras de gala" nas quais palavrões e brincadeiras sexuais são correntes - assim como ambientes pouco iluminados podem ser descritos por adjetivos como "brilhantes" (Leistner, 2014: 265).
13 | No Rio Grande do Sul, também é utilizada a expressão Exu Catiço para identificar exus evoluídos e coroados

$\mathbf{1 4}$ | Tendo como base a Jurema, Assunção (2004: 211) destaca a existência de um processo que, por um lado, procura moralizar as atitudes da entidade. Este pode ser identificado com os modos de evolução espiritual presentes na chamada "umbanda branca". Por outro, e em diálogo com o processo anterior, "a evolução proporciona o surgimento de novas entidades que passam a assumir aquele lado que foi 'rejeitado' pelo processo moralizador." 
Exus e pombagiras não se arrastam mais pelo chão, nem suportam mais cachaça barata, mas não deixam de se apresentar como mais próximos dos seres humanos que os procuram, "trabalhando" para quem "merece" e para ganhar "merecimento". Nessas condições, curto circuitando as linhas da evolução, os princípios umbandistas são instados a produzir uma outra modalidade de ação espiritual, a merecer um culto, o que se chama no Rio Grande do Sul de quimbanda.

\section{EXU CRUZADO}

Passemos ao "exu cruzado", novamente pedindo licença para citar outro trecho da tese de Leistner (2014: 143):

Até meados da década de 1960, os cultos dos Exus e Pombagiras no Rio Grande do Sul ainda encontravam-se balizados nas concepções umbandistas, até mesmo aqueles presentes na formação inicial da Linha Cruzada. (...) Contudo, as primeiras mudanças ocorrem já nesses templos sendo inicialmente observadas nos domínios do código ritual, especialmente no que se refere às inovações na feitura dos Exus. (...) Desse modo, se na versão umbandista aquelas divindades eram apenas toleradas nos templos para trabal har em troca da evolução espiritual, agora passavam a ter seus próprios assentamentos e receber a sacralização animal como recurso de mediação simbólica (...). A referência ao corte para os Exus é constante nas narrativas dos atores do campo afro-gaúcho como elemento fundamental na distinção entre uma concepção antiga e uma nova perspectiva de culto àquelas divindades (agora presentes na Linha Cruzada).

A isso, vale juntar como Barbosa (2012) resume o que lhe conta um pai-de-santo de Pelotas exatamente a propósito da feitura dos exus:

O exu torna-se então um "exu liberto, um exu mais evoluído", enquanto pelo lado da umbanda, nos diz ele, "o exu é torto". Fazer este espirito pelo lado da quimbanda é quebrá-lo, tornando-o "um exu pronto, que age mais", já aquele da umbanda, "é mais difícil de ser doutrinado, ele bebe no chão, se arrasta" (:43).

De acordo várias fontes, a feitura de exus e pombagiras é uma das características centrais da quimbanda atual. Isso implica a realização de sacrifícios animais para a produção de assentamentos que operam como vinculadores entre pessoas e entidades. Assim, um sacerdote ou uma sacerdotisa dedicados a rituais de quimbanda precisam ser iniciados (ou "aprontados") e estar vinculados a assentamentos correspondentes às entidades com as quais trabalham. Uma forma de entendermos os movimentos que estão em jogo nesse procedimento estabelecido é relacioná-los com alguns princípios do batuque, especificamente duas de suas noções, a de orixá e a de egum.

Como bem percebe Barbosa, "cruzar o exu (...) é dar a ele um tratamento ritual análogo àquele que é dado a um orixá" (2012:41). Mas exu já não é um orixá? Essa é uma questão complexa no batuque gaúcho. A entidade que corresponde a exu no panteão jeje-nagô recebe o nome de bará no batuque. Segundo Corrêa (2006: 182), "imagens e símbolos do Exu inexistem nas casas consideradas de Batuque 'puro'". Mas, de acordo 
com o mesmo pesquisador (ver também Barbosa, 2012: 248-52), o termo exu é utilizado de modo a revelar equivalências com bará. Outro ponto é que existem vários modos (ou "qualidades") de bará, e entre suas distinções uma das mais importantes é a que separa o da casa e o da rua. O "bará de casa" recebe um tratamento parecido com os demais orixás, mas o "bará da rua" tem poucos iniciados, mesmo estes prefere-se vincular "a um outro Bará mais calmo" (Corrêa, 2006:181). Considerando esses pontos, podemos sugerir que ao "cruzar o exu", a quimbanda está apontando para a presença problemática desse orixá no batuque. ${ }^{15}$ Mais do que isso, está, a modo de um curtocircuito, reformulando as distinções que mantêm separações entre exu e bará.

É importante salientar que, no batuque, Bará recebe uma deferência que não é a mesma que corresponde a Exu no candomblé. Entre as pessoas entrevistadas ao longo do processo de pesquisa que originou este artigo, temos Alexandre de Bará, Chaninho de Bará, Wesley de Bará Agelu, Pai Marquinho de Bará, entre outros. Ou seja, eles expressam uma realidade distinta daquela exposta por algumas etnografias do candomblé, pois Bará comumente ocupa seus filhos e atua como "dono da cabeça", assim como os outros orixás do Orumalé. Talvez o contraste com relação ao Exu observado por Roger Bastide (1959: 241) em outras regiões o tenha levado a afirmar, quando de sua vinda do Rio Grande do Sul, que haveria nessa parte do país "uma oposição enérgica à identificação de Bará com o diabo". Também é válido considerar o que Silva (2019: 144) aponta como sendo, "no Brasil, talvez o caso mais conhecido de culto público de Exu". Ele se refere a algo que constatamos nos mercados centrais de Porto Alegre e de Pelotas, lugares que abrigam, segundo narrativas bem disseminadas, assentamentos do Bará e que participam de atividades rituais públicas do batuque.

Voltemos agora aos exus da quimbanda, com a hipótese de que estes podem ter se beneficiado da deferência prestada no Rio Grande do Sul ao Bará. Um diálogo com o pai de santo Cesar de Xangô, cujo terreiro cruzado (umbanda, quimbanda e batuque) está situado na cidade de Alvorada, permite aventar essa hipótese ao tratar do assentamento como uma promoção. No momento que antecede o trecho citado a seguir, Pai Cesar falava sobre os sacrifícios que, "de umas décadas pra cá", começaram a ser feitos para os exus, havendo, portanto, uma aproximação dessas entidades com os modelos de oferenda feitas aos orixás e, ao mesmo tempo, se afastando das práticas presentes na chamada "umbanda branca". Na sequência, lamentando o "desaparecimento" de entidades centrais à umbanda, pai Cesar comenta sobre os sacrifícios de animais:

Não tem mais quase caboclo, preto velho menos ainda. Tem muito pouco e infelizmente tá se perdendo cada vez mais. Em algumas casas ainda estão nessa questão de evolução, trazendo as feituras de santo para dentro da umbanda. Tipo, fazendo corte, sacralização pra dentro da umbanda. Coisas que não eram assim um tempo atrás. Estão tentando dar um "up" na Umbanda de alguma forma, e aí trazendo o sangue, o axorô. ${ }^{16}$

15 | Esse é um ponto que se estende ao candomblé, como notam, em diferentes perspectivas, Barbosa (2012) Silva (2019) e Capone (2004)
16 | Entrevista, julho de 2018 concedida a Leonardo Almeida. 
Ou seja: uma vez atestado o crescimento da quimbanda e a evolução dos exus, uma maneira de evoluir ou expressar evolução é aproximar as entidades dos orixás no que diz respeito aos aprontamentos, sacrifícios e assentamentos. Nessa linha, torna-se possível supor que as vantagens evolutivas do exu quimbandeiro estão relacionadas à maneira como Bará é cultuado no batuque.

Esse fato, considerando o caso gaúcho, não parece revelar uma busca pela (re?) africanização das entidades da quimbanda, semelhante ao que foi destacado por alguns autores acerca do processo de busca por pureza ou traços e práticas mais africanizadas (Silva, 1995; Capone, 2004), em especial a partir da década de 1970 e tendo o candomblé como principal irradiador. Por outro lado, tal como foi destacado por Corrêa (2006), parece haver um reconhecimento do batuque como modalidade possuidora de maior poder simbólico. O exu, portanto, não ganha assentamentos, aprontamentos e sacrifícios para africanizar-se como tentativa de uma "busca às origens", mas para adquirir poder simbólico e potencial evolutivo através dos princípios já assumidos pelo batuque. $O$ mesmo se estende aos eguns, cultuados na quimbanda não como signo de africanização, mas em função de deslocamentos em relação ao batuque.

Na cosmologia batuqueira, os eguns são espíritos de mortos, fontes de potenciais perturbações para os vivos. Por tal razão, recebem um tratamento que visa neutralizar seus perigos. A quimbanda associa os eguns ao espírito de pessoas que viveram situações trágicas, sobretudo quando isso resultou de suas deliberações. Mas propicia também formas de recuperação, pelo assentamento dessas entidades. Apesar do assentamento sugerir uma aproximação com os orixás, a quimbanda mantém uma distinção importante entre exus/pombagiras e eguns. Essa distinção remete àquela que a umbanda constrói entre caboclos e pretos-velhos, de um lado, e, de outro, exus. Mas também - assim pode-se vê-la, para mantermos a metáfora do curtocircuito - reelabora o estatuto atribuído aos eguns pelo batuque. Pois na quimbanda encontra-se a configuração do "exu assentado com o carrego de eguns". Ou seja, não se trata apenas de fixar (e de isolar) o egum para que trabalhe para o terreiro, mas de associá-lo a algo que, lembremos do "exu cruzado", recebe dedicação ritual análoga àquela que é dada a um orixá.

Os deslocamentos condensados nas noções de "exu da alta" e "exu cruzado" têm paralelos com arranjos espaciais característicos da quimbanda. Como a configuração demandada pelos rituais de umbanda (mas não do batuque), as sessões de quimbanda ocorrem em salões que mantêm uma separação entre a parte dos médiuns e a parte da assistência. Após a incorporação ritual das entidades e seu bailado ao som de pontos, exus e pombagiras ("evoluídos") ficam disponíveis para consultas destinadas a ajudar os que frequentam as sessões ou deles receber presentes. Mas, se não for improvisado, o lugar onde ocorrem essas sessões deve providenciar espaços onde estão depositados os assentamentos das entidades ("cruzadas"). O exemplo destacado por Leistner (2014) é o de um terreiro que têm casinhas separadas para os exus, para os barás e, elas 
mesmas distintas, para os eguns do batuque e os eguns da quimbanda. Em geral, a configuração espacial é mais simples, sem deixar de afirmar a distinção entre espaços internos e outros externos. Tal distinção não é exigida em casas de umbanda, mas é esperada em terreiros de batuque - com a diferença de que na quimbanda o exu não fica apenas do lado de fora.

A dimensão espacial oferece ainda a oportunidade de retomarmos o tema da autonomia da quimbanda. Quando Leistner (2014) descreve uma sessão de exus como a célula básica do que seria o "código ritual" da quimbanda (:235ss), o espaço onde ela se desenrola é, na verdade, um terreiro de linha cruzada. Há sacerdotes e sacerdotisas de quimbanda cujo nomes incorporam as principais entidades a que se dedicam, mas são mais raros os templos exclusivamente atribuídos aos seus rituais. O terreiro de Mãe Rita em Pelotas seria um exemplo, mas Barbosa (2012) nota como a sacerdotisa foi também iniciada na umbanda, cujas atividades frequenta em uma casa cuja mãe se aprontou no batuque. O mais comum é que sessões de quimbanda ocorram em espaços cujos salões mantêm três altares, um para os orixás, outro para os caboclos e pretos-velhos, e ainda outro para exus e pombagiras. Em suma, a quimbanda, para ser praticada, não exige um espaço próprio e exclusivo, demandando apenas adaptações a partir de disposições estabelecidas pela umbanda e pelo batuque.

Em razão do que expusemos acima, encontramos razões para afirmar que a quimbanda existe de uma forma que, por ora, não depende ou exige sua autonomia. 0 que a define é o culto de entidades conhecidas como exus e pombagiras, secundadas pelos eguns. Buscamos mostrar que esse culto exige condições que podem ser estabelecidas quando observamos os deslocamentos operados a partir de princípios que caracterizam, axialmente, a umbanda, por um lado, e o batuque, por outro. As figuras do "exu da alta" e do "exu cruzado" correspondem a esses deslocamentos e abrem os caminhos para entendermos como exus e pombagiras podem receber um culto específico. Específico não significa autônomo. Pois parece-nos que a quimbanda existe, apresentando-se como outra coisa, na medida em que depende de princípios desenvolvidos por formas do culto dos orixás mais estabelecidas no Rio Grande do Sul. ${ }^{17}$

\section{EXUS, MÍDIA E EXPOSIÇÃO}

A constituição do "exu quimbandeiro" envolve um processo pelo qual essa entidade, por meio de seus "cavalos", passou a valorizar a complementaridade entre evolução e exposição. Manifestar-se com pompa e realeza, nessa lógica, significa validarse como exu evoluído, condensando tanto o sentido de força e de magia, quanto o de merecimentos. O exu tornou-se vaidoso e buscou, também como parte de seu processo evolutivo, aprender as melhores maneiras de se expor. Vale citar um dos casos em que essa exposição nos foi apresentada pelas quimbandas gaúchas.
$\mathbf{1 7} \mid$ Vale reforçar essa observação com a constatação de Leistner (2012: 283) quando nota que o vínculo de pessoas com a quimbanda não inclui um "processo de formação de uma identidade política coletiva", como evidencia a ausência do termo "quimbanda" do nome das várias federações afro-religiosas gaúchas.


Em Viamão, cidade da região metropolitana de Porto Alegre, o terreiro do pai de santo Daniel de Xangô iniciava, por volta das 20 h do dia 9 de junho de 2018, a chamada dos exus que iriam participar da grande festa de quimbanda destinada ao Exu Rei das Sete Encruzilhadas, entidade incorporada por Pai Daniel. Os exus que naquele momento chegavam ao terreiro haviam sido previamente convidados a compor o cortejo, uma espécie de "entrada triunfal" do exu dono da festa e seus convidados mais especiais. A grande festa, que seria celebrada ainda naquela noite, não aconteceria no terreiro, embora fosse uma comemoração da data de assentamento do Exu de Daniel, ocorrida originalmente 18 anos antes. A poucas quadras dali a sede da escola de samba Vila Isabel, alugada especialmente para o evento, já estava preparada para receber o Exu Rei das Sete Encruzilhadas e seu cortejo, bem como outros convidados, médiuns, curiosos e moradores das proximidades. ${ }^{18}$

Enquanto as incorporações começavam no terreiro, a equipe de alabês que seria responsável pela condução musical já iniciava seus toques no local da festa. Ao passo em que os pontos de exu eram cantados, mais convidados chegavam. A equipe se acomodava sobre um palco montado em uma das extremidades do salão, diante da entrada principal. Tratava-se de uma plataforma coberta por um tecido preto e, sobre ele, armações de ferro acomodavam canhões de luz de cores e rotações variadas, tudo para contribuir na produção do ambiente. Jogos de luz, chuva de prata, jatos de fumaça e decorações pomposas são elementos que se tornaram comuns nas festas de quimbanda no Rio Grande do Sul. Dizem os quimbandeiros: "é assim que os exus gostam".

Por volta de uma da manhã, a corte do Exu Rei das Sete Encruzilhadas começou a se deslocar do terreiro ao local da festa. Enquanto os exus caminhavam pelas ruas do bairro, os convidados se reposicionavam no grande salão da Vila Isabel até que fossem formadas duas fileiras em lados opostos, de modo a compor um corredor que ligava a entrada principal ao palco onde estavam alabês e tambores. Os casais que formavam a corte entravam em sequência, uma dupla após a outra, e tinham seu momento de dança diante dos tambores e admiradores.

Seu Sete, o último a entrar, vestia-se como rei. Diante dos tambores, após atravessar o corredor cheio de admiradores, a entidade dançou e, como é comumente dito nas quimbandas de Porto Alegre, "fez sua magia". Em meio às quase mil pessoas que assistiam a performance do exu, funcionários de diferentes empresas de mídia contratadas faziam o registro em foto e em vídeo, além de transmissões ao vivo pelo Facebook, em suas respectivas "páginas oficiais". A contratação de empresas de mídia com trabalho exclusivamente dedicado à clientela de terreiros se tornou comum a partir de $2010^{19}$, em boa medida incentivadas pelo crescimento da quimbanda no Rio Crande do Sul e pelo comportamento intensamente expositivo dos exus e pombagiras. Essas empresas utilizam recursos como fotos publicadas no Facebook, transmissões ao vivo, produção de clipes e documentários, e outros recursos para compor, a partir do trabalho conjunto desses ingredientes, o que é comumente chamado de cobertura de mídia e, 
assim, estender a presença dessas entidades para além dos rituais no terreiro. Além disso, a contratação dessas empresas é também compreendida como um merecimento, um presente dado à entidade pelos trabalhos prestados e pela evolução alcançada.

O próximo momento da festa, após o cortejo, seria um dos mais esperados, quando o anfitrião permitiria fotos com seus convidados em um espaço cuidadosamente preparado. Ao lado do palco, um cenário de realeza foi montado (cf. foto abaixo). Era possível ver uma plataforma circular e, sobre ela, um tapete vermelho com detalhes pretos. Nas extremidades da plataforma, luzes cuidadosamente posicionadas iluminavam o trono dourado e de estofado vermelho. Era possível ver uma mesa com flores vermelhas e uma garrafa de uísque dentro de um balde metálico com gelo, bem diante do trono onde Seu Sete posaria com seus convidados. Quatro fotógrafos de empresas de mídia se posicionavam diante do exu em busca das melhores imagens e, ao lado, uma grande fila era formada por admiradores à espera de um breve momento com a realeza.

No momento seguinte, após as fotos no "cenário", o dono da festa se juntaria aos outros exus e pombagiras no salão para dançar, conversar com admiradores e clientes e, também, para tirar mais fotos com seus amigos. $O$ exu anfitrião "puxava o fotógrafo pelo braço", pedindo que tirasse mais fotos com seus convidados. Ele

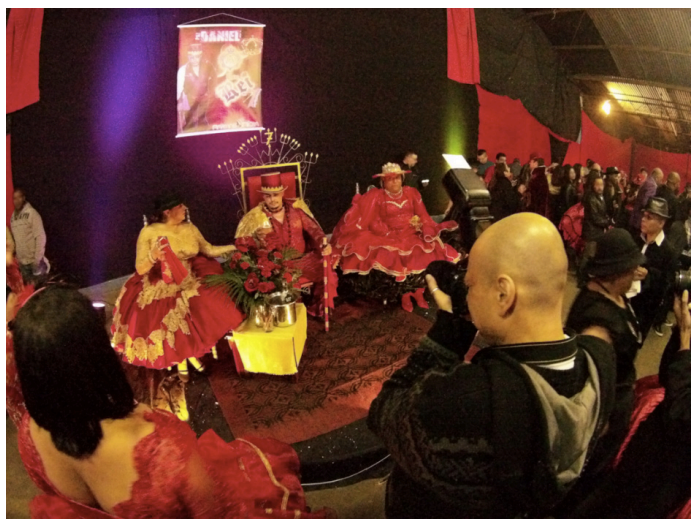

Seu Sete e suas amigas (entidades) sendo fotografados pelas empresas de mídia. andava para a esquerda, percebia a presença de um exu amigo e dizia: "agora aqui". Virava-se e atravessava o salão: "tira uma aqui com o Veludo". Em cada parada, uma foto e uma pose, prática que se tornou recorrente entre os exus portoalegrenses. É comum, portanto, que ao buscarmos imagens de uma mesma entidade nas paginas oficiais e perfis das empresas de mídia na internet, ela seja vista em diversas situações e festas expondo-se a partir da mesma pose. Alguns exus se ajoelham e erguem o copo de uísque. Outros, abaixam a cabeça até que o chapéu esconda seus olhos por completo e tocam levemente a aba com a ponta dos dedos. As poses se tornaram marcas de exposição dessas entidades e, tal como buscamos argumentar, marcas de evolução.

Fernando ${ }^{20}$, dono da empresa Afro Mídia, reafirma que essa necessidade de exposição dos exus e sua participação ativa junto às mídias só é possível porque os exus evoluíram.

Exu que não evolui, não gira mais. A imagem entra dentro dessa evolução. O exu vinha uma vez por mês, uma vez por semana. Eera todo entrevado num canto, tomava só cachaça 
com cinza. Hoje em dia não, toma um bom Red Lable, toma uma cerveja. E a fotografia entra nessa evolução. Ele [o exu] quer registrar.

A partir de um movimento quase coreografado, a justificativa apresentada pelos religiosos para essa "vontade de aparecer" dos exus é quase sempre a mesma: "os exus são os que mais se aproximam de nós", os vivos. Essa proximidade, que se manifesta em diversos aspectos de seus comportamentos, se estende também ao uso das mídias. Pai Geison de Xangô disse que os exus "são do nosso mundo, pois não são das florestas como os caboclos, não são do orum como os orixás. Os exus são das ruas e das festas, gostam dos nossos assuntos e passaram pelos desafios que nós passamos. Sendo os mais próximos de nós, eles gostam das mídias que gostamos". ${ }^{21}$ Pai Geison, assim como Pai Daniel e outros, afirma que os exus sentem, "em sua espiritualidade", seu prestígio e reconhecimento sendo ampliados pela atuação das mídias. As entidades "aprenderam que isso é bom" e buscaram estender sua presença também virtualmente. Onde quer que sejam vistos, os exus querem conquistar admiradores e clientes, mostrar beleza, poder e desenvoltura em suas práticas mágicas.

É importante destacar que há, no Rio Grande do Sul, uma compreensão amplamente compartilhada de que as diferentes divindades (entidades ou orixás) expressam distintas relações com as mídias. Segundo Alberto Flores, fundador da empresa de mídia Grande Axé, as entidades da umbanda, principalmente os caboclos, não demonstram interesse pelo registro de sua imagem e, em alguns casos, são "arredios". Os orixás, segundo as tradições do batuque, não podem ser filmados ou fotografados após sua chegada ao terreiro. A quimbanda, por outro lado, é a modalidade ritual que mais se aproveitou dos usos das novas mídias, pois, comenta Alberto, "o exu gosta de aparecer"22. Rafael Luz, dono da empresa Planeta África, comenta sobre a produção de imagens: "O santo a gente nem fotografa e o caboclo não reage tanto a isso, nem nos vê na festa. As outras entidades da umbanda, preto velho, etc, entra junto, não dão bola. Já o exu, não, o exu na quimbanda já interage até de foto, nos pede pra tirar foto."23

No caso dos exus quimbandeiros, diferente dos orixás e das entidades da umbanda, há um regime de imagem em que o comportamento da entidade é marcado pelo ato de exposição. Tal regime se manifesta no universo da performance, como um jeito de ser constitutivamente expositivo. Nesse caso, aprimorar a interação com as mídias e elaborar maneiras de potencializar a exposição também são sinais de evolução. E aqui é importante lembrar do que diz Rabelo (2015) acerca da visão no candomblé. A autora destaca que as religiões afro-brasileiras atuam a partir de dinâmicas de vere ocultar, muitas vezes em processos em que o visível e o invisível encontram-se dispostos em camadas sobrepostas ou distribuídos em diferentes espaços. Assemelhando-se aos orixás, o exu assentado da quimbanda gaúcha deve ser oculto na "casinha dos exus", acessível apenas a alguns, enquanto que, afastando-se das divindades africanas, uma de suas outras partes, a entidade incorporada, deve ser exposta.
21 | Entrevista, setembro
de 2018, concedida a de 2018, concedida a
Leonardo Almeida.

22 | Entrevista, março de 2017. concedida a Leonardo Almeida.

23| Entrevista, agosto de 2017, concedida a Leonardo Almeida. 
O que está em questão aqui, em sintonia com certos debates teóricos que buscam considerar a importância da estética ${ }^{24}$ para o estudo das materialidades religiosas (Giumbelli, Rickli e Toniol, 2019; Morgan, 2011; Van de Port, 2016), é a recusa da separação entre forma e conteúdo. Nesse sentido, consideramos que as "mídias", entendidas como uma categoria êmica, não são extrínsecas à evolução dos exus. Dito de outra maneira, uma imagem, por exemplo, que pode ser compreendida como um dos elementos constituintes das "mídias", não é apenas um intermediário entre o exu

$\mathbf{2 4}$ | Estética é aqui pensada a partir da compreensão aristotélica de aisthesis, como uma crítica a noção de estética ligada à ideia do "belo", e refere-se a

"nossa experiência sensorial total do mundo e nosso conhecimento sensível dele" (Meyer e Verrips, 2008: 21). evoluído e sua exposição. Tampouco é apenas um mediador que transforma uma mensagem no momento do encontro e, em seguida, se retira, evidenciando de maneira externa um trabalho por ela feito. Em suma, mensagem e meio se confundem, pois, a cada incremento estético, como no caso de uma imagem clareada com o auxílio de programas de edição ou quando uma pose performatizada toma a forma de uma fotografia oficial, observamos uma expressão e uma das maneiras de materialização da força e dos merecimentos dos exus. Evolução não é apenas uma bela dança do exu no salão; é, também, a dança sendo exposta a partir do aprimoramento da relação que os exus possuem junto às mídias (lembremos das poses) e que, dessa maneira, são reunidos de forma indissociável em uma imagem. Trata-se de importantes componentes de distinção entre os exus/pombagiras e as entidades cultuadas na umbanda e no batuque (caboclos, pretos velhos, orixás, etc), cuja presença junto à mídia não se manifesta a partir dos mesmos sistemas de relação e evolução. Isso explicaria, em parte, o crescimento conjunto e interdependente da quimbanda e das empresas de mídia no Rio Grande do Sul, bem como os usos diferenciados das mídias nas modalidades religiosas ou formas rituais que compõem o campo afro-gaúcho.

\section{DEIXANDO CAMINHOS ABERTOS}

Buscamos neste artigo mostrar as condições que dão possibilidade a assim chamada quimbanda no contexto do campo afro-religioso gaúcho. Em nosso argumento, as entidades cultuadas pela quimbanda constituem-se a partir de deslocamentos em princípios que remetem a duas outras modalidades mais estabelecidas, a umbanda e o batuque. Para tanto, é central a ideia de evolução dos exus (e pombagiras), definida seja pela elevação do marginal, seja pelo assentamento diferenciado. Isso permite que exus e pombagiras possam ser cultuados em rituais específicos. Faz parte da dinâmica desses rituais uma certa relação entre ocultação e revelação. Ao passo que os assentamentos - de que também dependem as entidades da quimbanda - mantêm-se reservados, a manifestação dos exus e pombagiras, especialmente em ocasiões festivas, depende de uma superexposição. Esse modo de exposição institui uma continuidade entre princípios espirituais (especialmente, "evolução") e formas materiais (o que no campo das práticas se chama de "cobertura de mídia"). 
Dar atenção à quimbanda gaúcha é, em nosso entendimento, uma via para conferir visibilidade a modalidades rituais que se distinguem dos modelos religiosos mais estabelecidos - no contexto local, batuque e umbanda. Se voltarmos aos dados resultantes do mapeamento de terreiros referido no início deste artigo (Brasil, 2011), vamos perceber uma recorrência: junto a termos que correspondem àqueles modelos mais estabelecidos (umbanda, de um lado, candomblé/nagô/xangô/tambor de mina, de outro), há sempre outros com expressão variável e localmente específica. Em Belém, temos "pena e maracá", "mina de caboclo" e "pajelança"; em Recife, a "jurema"; em Belo Horizonte, "omolocô". Enquanto as quatro primeiras categorias mostram a presença de componentes indígenas, a última nomeia uma modalidade que, como a quimbanda, é geralmente descrita como uma forma híbrida. Nosso enfoque da quimbanda aposta em uma perspectiva que não apenas recusa ver tais modalidades como anomalias, mas também não se contenta em caracterizá-las como híbridas sem a devida investigação dos processos que as constituem.

O caso da quimbanda mostra como ainda há caminhos para problematizarmos as formas assumidas por exu. Desde Carneiro (1950), pelo lado do candomblé, e desde Ortiz (1978), pelo lado da umbanda, inúmeros trabalhos investem nisso. Confundindo-se com o movimento, esse orixá é também a chave para compreendermos-utilizando-se a expressão de Barbosa (2012) - as variações contínuas que caracterizam as múltiplas modalidades religiosas que o incorporam. Ao acompanhar essas multiplicidades, percebemos que formas híbridas são reveladoras não por serem a síntese de formas puras, mas porque permitem ver o quão longe se pode ir a partir do que aparece como uma simples oposição. Ao privilegiar a quimbanda, pretendemos mostrar as dinâmicas que expandem concepções associadas à umbanda (evolução) e ao batuque (feitura). 0 caminho para isso foi exu, ser que, em seus modos e lugares de atuação, esculhamba a linearidade e a pureza dos cursos únicos (Rufino, 2018) e é notado pelo movimento, pelos fluxos e cruzamentos, pela recusa de identidades estáticas. Acreditamos que tal procedimento aponte pistas para se compreender outras transformações que tenham nesse orixá o seu protagonista.

Emerson Alessandro Giumbelli é Professor Titular da Universidade Federal do Rio Grande do Sul, atuando no Departamento de Antropologia e no Programa de PósGraduação em Antropologia Social. Integra o Núcleo de Estudos da Religião na UFRGS. É bolsista de produtividade do CNPq.

Leonardo Oliveira de Almeida é pesquisador DCR (Desenvolvimento Científico Regional) - CNPq/FUNCAP no Programa de Pós-Graduação em Antropologia da 
Universidade Federal do Ceará. É doutor em Antropologia Social pela Universidade Federal do Rio Grande do Sul.

CONTRIBUIÇÃO DE AUTORIA: Leonardo Almeida realizou sua pesquisa de doutorado sob a orientação de Emerson Ciumbelli. Dados da pesquisa de tese de Oliveira são parte do texto, assim como a respectiva análise. Reflexões mais gerais, estruturação do texto e diálogos com a literatura mais ampla sobre religiões mediúnicas são a contribuição de Giumbelli. Interlocuções com referências mais específicas sobre religiões afro-gaúchas são de autoria de ambos.

FINANCIAMENTO: Coordenação de Aperfeiçoamento de Pessoal de Nível Superior (CAPES), Conselho Nacional de Desenvolvimento Científico e Tecnológico (CNPq).

\section{REFERÊNCIAS BIBLIOGRÁFICAS}

ALMEIDA, Leonardo Oliveira de. 2019.

Tambores de todas as cores: práticas de mediação religiosa afro-gaúchas. Porto Alegre, Tese de Doutorado, Universidade Federal do Rio Grande do Sul.

ANJOS, José Carlos Comes dos. 2006. No território da linha cruzada: a cosmopolítica afro-brasileira. Porto Alegre, Editora da UFRGS/Fundação Cultural Palmares.

ASSUNÇÃO, Luiz. 2004. "Os Mestres da Jurema". In. PRANDI, Reginaldo (Org.). Encantaria brasileira: o livro dos mestres, caboclos e encantados. Rio de Janeiro-RJ, Pallas, pp. 183-215.

BARBOSA NETO, Edgar Rodrigues. 2012. A máquina do mundo: variações sobre o politeísmo em coletivos afro-brasileiros. Rio de Janeiro, Tese de Doutorado, Universidade Federal do Rio de Janeiro.

BASTIDE, Roger. 1959. A Sociologia do Folclore Brasileiro. São Paulo, Editora Anhembi.

BEM, Daniel Francisco de. 2012.Tecendo o axé: uma abordagem antropológica da atual transnacionalização a fro-religiosa nos países do Cone Sul. Porto Alegre, Universidade Federal do Rio Grande do Sul.

BIRMAN, Patricia. 1997. "O campo da nostalgia e a recusa da saudade: temas e dilemas dos estudos afro-brasileiros". Religião e Sociedade, v. 18, n. 2: 75-92.

BRASIL. 2011. Alimento: Direito SagradoPesquisa Socioeconômica e Cultural de Povos e Comunidades Tradicionais de Terreiros. Brasília: Ministério do Desenvolvimento Social e Combate à Fome; Secretaria de Avaliação e Gestão da Informação.

BRUMANA, Fernando; MARTINEZ, Elda. 1991. Marginália Sagrada. Campinas, Editora Unicamp.

CAPONE, Stefania. 2004. A busca da

África no candomblé: tradição e poder no Brasil. Rio de Janeiro, Pallas Editora.

CARNEIRO, Edison. 2005."Um orixá caluniado". In: CARNDEIRO, Edison (org.) Antologia do negro brasileiro. Rio de Janeiro, Agir, pp. 397-400. 
CARVALHO, José Jorge. 1995. “A experiência histórica dos quilombos nas Américas e no Brasil." In: CARVALHO, José Jorge; DORIA, Siglia Zambrotti e OLIVEIRA JÚNIOR, Adolfo Neves de. (orgs.). O Quilombo do Rio das Rãs. História, tradições, lutas. Salvador, EDUFBA, pp.13-73.

CHIESA, Gustavo. 2012. "Criando mundos, produzindo sínteses: experiência e tradição na Umbanda". Debates do Ner, v. 21: 205-238. https://doi.org/10.22456/1982-8136.26495

CORRÊA, Norton. 2006. O Batuque no Rio Grande do Sul: Antropologia de uma religião afro-rio-grandense. São Luiz, Cultura\&arte.

ENGELKE, Matthew. 2010. "Religion and the media turn: a review essay". American Ethnologist, v. 37, n. 2: 371-379. https://doi. org/10.1111/j.1548-1425.2010.01261.x

GIUMBELLI, Emerson. 1997. O Cuidado dos mortos: uma história da condenação e legitimação do espiritismo. Rio de Janeiro, Arquivo Nacional.

GIUMBELLI, Emerson; RICKLI, João; TONIOL, Rodrigo (Orgs.). 2019. Como as coisas importam: uma abordagem material da religião - textos de Birgit Meyer. Porto Alegre, Editora da UFRCS.

LEISTNER, Rodrigo Marques. 2014. Os outsiders do além: um estudo sobre a quimbanda e outras 'feitiçarias' afro-gaúchas. São Leopoldo, Tese de doutorado, Universidade do Vale do Rio dos Sinos.

MACGIE, Yvonne. 1992. Medo do feitiço: relações entre magia e poder no Brasil. Rio de Janeiro, Arquivo Nacional.

MEYER, Birgit; VERRIPS, Jooda. 2008. "Aesthetics". In: MORGAN, David. (org.). Key Words in Religion, Media, Culture. Londres/ Nova York, Routledge, pp. 20-30.
MEYER, Birgit. 2020. "Religion as

Mediation". Entangled Religions, v. 11, n.

3. https://doi.org/10.13154/er.11.2020.8444

MORGAN, David. 2012. The Embodied Eye. Religious visual culture and the social life offeeling. Berkeley, University of California Press.

ORTIZ, Renato. 1978. A morte branca do feiticeiro negro. Petrópolis, Vozes.

RABELO, Miriam. 2015. "Aprender a ver no candomblé". Horizontes Antropológicos, n. 44: 229-251. http://dx.doi.org/10.1590/ So104-71832015000200010

RUFINO, Luiz. 2018. "Pedagogia das encruzilhadas". Periferia, v. 10, n. 1, p. 71-88. https://doi.org/10.12957/periferia.2018.31504

SERRA, Ordep Trindade. 1995. Águas do Rei. Petrópolis, Vozes.

SILVA, Suziene David da. 2003. A quimbanda de mãe leda: religião afro-gaúcha de exuse pombas-giras. Recife, Dissertação de Mestrado, Universidade Federal de Pernambuco.

SILVA, Vagner Gonçalves da. 1995. Orixás da metrópole. Petrópolis, Vozes.

SILVA, Vagner Gonçalves da. 2019. Exu: 0 guardião da casa do futuro. Rio de Janeiro, Pallas.

STOLOW, Jeremy. 2005. "Religion and/as Media”. Theory, Culture \& Society, v. 22, n. 4: 119145. https://doi.org/10.1177/0263276405054993

TEIXEIRA, Talita Bender. 2005. Trapo Formoso: o vestuário na Quimbanda. Porto Alegre, Dissertação de Mestrado, Universidade Federal do Rio Grande do Sul.

VAN DE PORT, Mattijs. 2016. “Expondo exu: algumas notas sobre práticas de exposição em religião, artes e ciências". In: FONSECA, Claudia; ROHDEN, Fabíola; MACHADO, Paula Sandrine e PAIM, Heloísa Salvatti. (orgs.) 
artigo | Emerson Alessandro Giumbelli, Leonardo Oliveira de Almeida | O Enigma da quimbanda:

formas de existência e de exposição de uma modalidade religiosa afro-brasileira no Rio Grande do Sul

Antropologia da Ciência e da Tecnologia, dobras

reflexivas. Porto Alegre: Sulina, pp. 99-116.

Recebido em 3 de julho de 2020. Aceito em 18 de março de 2021. 